\title{
A history of collaboration in research and health care
}

\section{Louis-Philippe Boulet MD FRCPC FCCP, President, Canadian Thoracic Society}

$\mathrm{C}$ anada has a long history of collaboration among both clinicians and researchers, but recently, such interaction has been promoted even more vigorously. Working in such a large country does not facilitate the process, but with the development of communications such as electronic mail, the Internet and other means of rapid transfer of information, it has become much easier. The exchange of expertise and the transfer of technologies have enormous potential to improve the quality and speed of research, as well as to translate the resulting developments more effectively into improved care.

From the more informal collaborations that were developed in the past, we have evolved toward more structured ways to improve and organize such collaborative work. At the national level, for example, the Canadian Institutes of Health Research (CIHR) has developed programs to improve links between researchers. The Circulatory and Respiratory Institute, in collaboration with the Heart and Stroke Foundation of Canada and other partners, recently developed the New Frontiers Program, which offers a unique opportunity for researchers to meet and discuss the important questions that will help to forge an integrated health research agenda for circulatory and respiratory health. The results of this program were announced last July and are available on the Web at <http://www.cihr.ca>, and various cardiorespiratory projects were supported. In the field of respiratory disorders, proposals on proteomics, chronic obstructive pulmonary disease (COPD), teenage smoking, children's respiratory emergencies, sleep-related cardiorespiratory disorders, organ transplantation, critical care and gene- and/or cell-based treatments were successful.

Not only are established groups of researchers encouraged to collaborate, but the integration of an expanded multidisciplinary component into new programs, with participants from different fields of research, may help to provide new viewpoints and innovative ways to integrate research developments into current care, particularly in addressing the needs of the Canadian population. For example, another CIHR initiative, the New Emerging Team Grant Program, is a collaborative effort between eight CIHR institutes and external partners. The New Emerging Team Grant Program aims to supply support funds for the creation or development of new competitive research teams that will, in turn, have the potential to apply for and receive infrastructure team funding The following are also among its goals: to support multidisciplinary and crosstheme research; to support

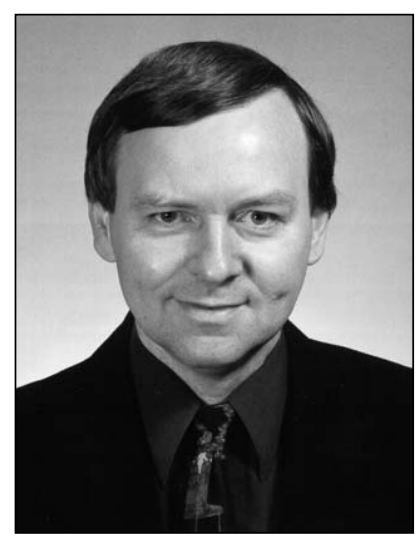
the training and establishment of new investigators in identified areas of focus; and to create a team environment to favour the development of new, fundable research projects.

Efforts to give structure to research activities are also evident at the provincial level. For example, the provincial health research networks of the Fonds de la recherche en santé du Québec (Quebec Research Fund), developed more than six years ago, have provided support for the development of provincial networks such as the Respiratory Health Network. The aim of this network is to promote collaboration among basic scientists, clinical researchers and clinicians from different universities. Of particular note among their various initiatives were the implementation of a 'research plan', the establishment of a 'tissue bank' and support for a provincial 'laboratoire de télématique' or telematics laboratory (data communications) that provides Web-based support for various research initiatives.

Along the same lines, a variety of groups looking at specific diseases have emerged in the past few years, either independent or affiliated with societies, such as the Canadian COPD Alliance, the Canadian Sleep Society, the Canadian Critical Care Society and many others. They foster not only collaborative research, but also integrated care, and sometimes patient and/or public education. The Clinical Trials Group recently proposed by the Canadian Thoracic Society also follows this trend. 
Finally, large population disease management projects, such as 'Improving Cardiovascular Outcomes in Nova Scotia' (ICONS, Nova Scotia), 'Alberta Strategy To Help Manage Asthma' (ASTHMA, Alberta), 'Vers l'excellence dans les soins aux personnes asthmatiques' (VESPA, Quebec), 'Programme régional intégré d'information, de suivi médical et d'enseignement' (PRIISME, Quebec) and others developed with the support of health authorities, universities and industry, are very promising. They are offering new ways to improve care, particularly in targeting key problems and those regions or people who need the most support; providing new ways to update caregivers' knowledge and skills based on current consensus guidelines; and providing additional support for evaluative research in applied care.
This accelerated trend in the development of infrastructures to help create a synergy between researchers and others should lead to an optimization of resources, speed up the process of discovery and possibly help to reduce health care costs while improving our population's health and quality of life. The next few years will reveal whether these efforts have been fruitful. Many of these collaborations have already produced enviable results, but additional efforts should be made to help other initiatives reach the height of expectations. That being said, we certainly should not withdraw support, in any way, from individual researchers. In the past, researchers working in isolation have often produced valuable discoveries or essential basic observations that ultimately led to important new developments. An adequate balance is needed to ensure the optimal use of resources. 


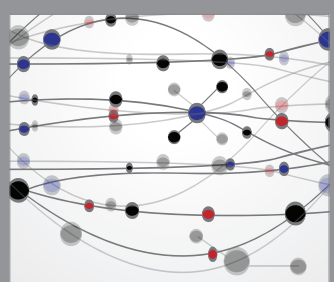

The Scientific World Journal
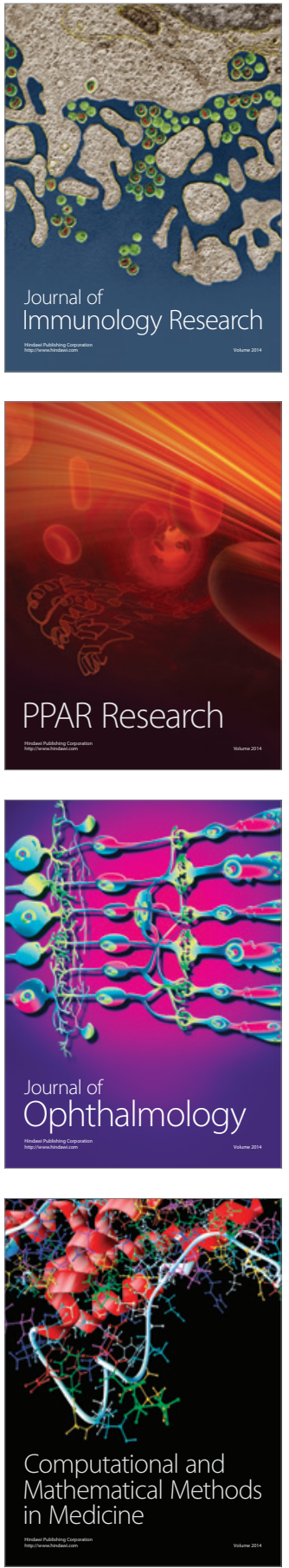

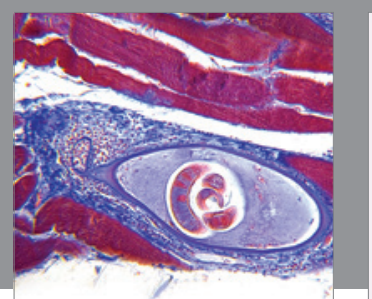

Gastroenterology Research and Practice

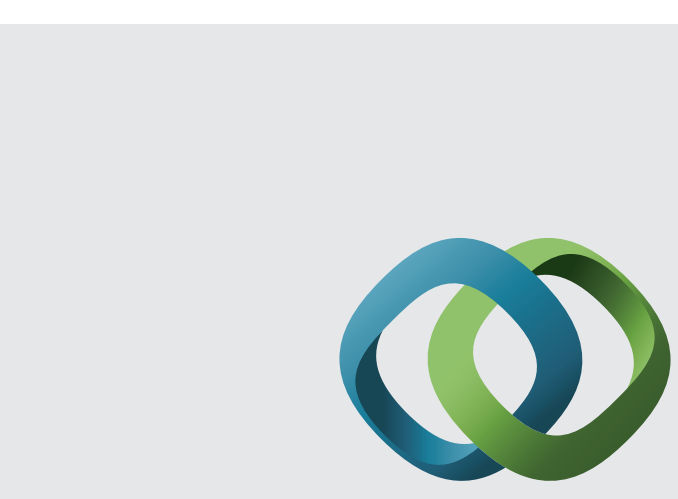

\section{Hindawi}

Submit your manuscripts at

http://www.hindawi.com
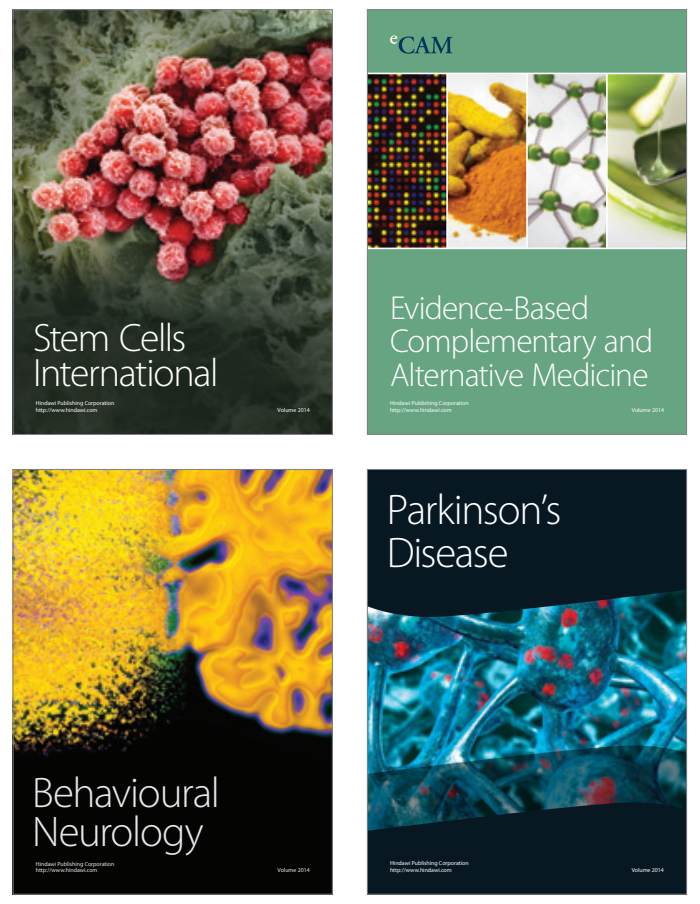
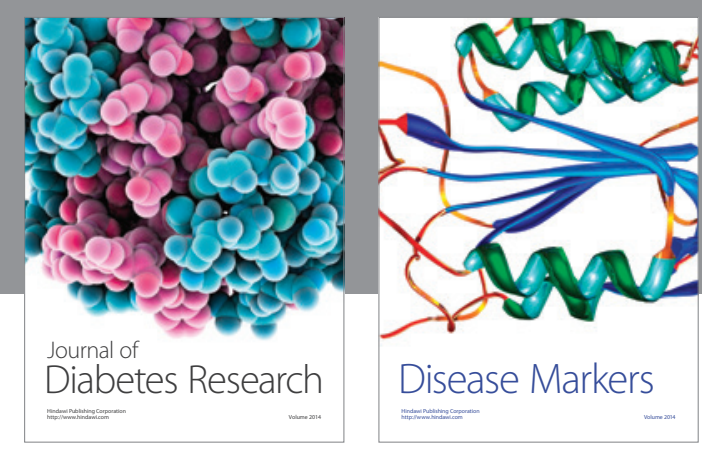

Disease Markers
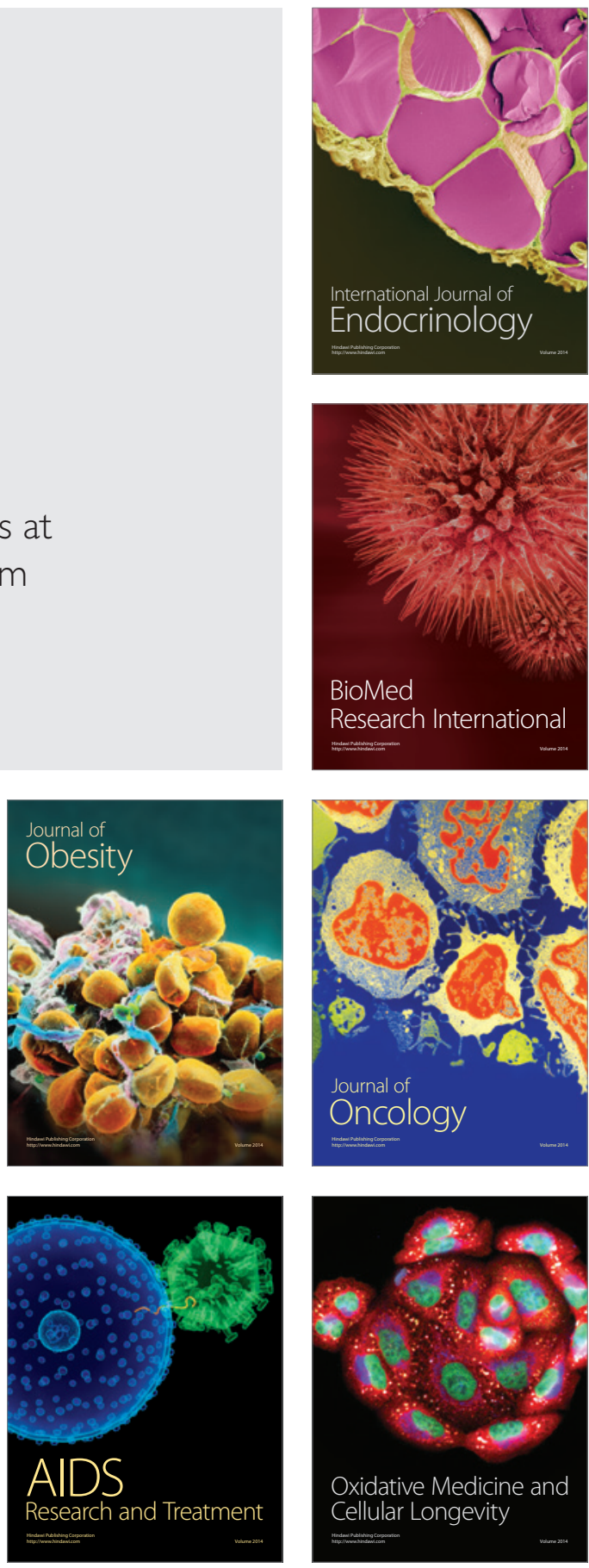